\title{
Safe Design Suggestions for Vegetated Roofs
}

\author{
Michael Behm
}

\section{Abstract}

Rooftop vegetation is becoming increasingly popular due to environmental benefits and its ability to earn green building certification credits. With the exception of one international guideline, there is little mention of worker safety and health in vegetated roof codes and literature. Observations and field investigations of nineteen vegetated roofs in the United States revealed unsafe access for workers and equipment, a lack of fall protection measures, and other site specific hazards. Design for safety strategies and the integration of life cycle safety thinking with green building credits systems are preferred methods to reduce risk to workers on vegetated roofs. Design suggestions have been developed to add to the body of knowledge. The findings complement several National Institute for Occupational Safety and Health (NIOSH) Construction and Prevention through Design (PtD) goals, are congruent with NIOSH's Safe Green Jobs initiative. Organizations who install and maintain vegetated roofs can utilize the findings to understand hazards, take precautions, and incorporate safety into their bids.

Keywords. Vegetated roof, safe design

Published version: Behm, M. (2012). "Safe Design Suggestions for Vegetated Roofs." J. Constr. Eng. Manage., 10.1061/(ASCE)CO.1943-7862.0000500, 999-1003.

\footnotetext{
${ }^{1}$ Associate Professor, East Carolina University, Department of Technology Systems, Greenville, NC 27858. E-mail: behmm@ecu.edu
} 


\section{Background}

Vegetated roofs are becoming increasingly popular in the United States for their environmental benefits and their ability to earn credits in the green building certification process. Additionally, municipalities are providing tax incentives to encourage vegetated roof installation and passing regulations that require government buildings to provide vegetated roofs. Vegetated roofs have been proven to provide environmental benefits. They have been shown effective at reducing:

1. air pollution (Li et al, 2005; Yang et al, 2008);

2. energy use in buildings (Castleton et al 2010; Kumar and Kauschik, 2005),

3. runoff from roof surfaces as a stormwater management practice (Hilten et al, 2008; Mentens et al, 2006; Villarreal and Bengtsson, 2005); and

4. the urban heat island effect (Rizwan et al, 2008; Takebayashi and Moriyama, 2007).

Vegetated roofs can directly provide building owners with numerous LEED credits in the subcategories of reduced site disturbance, site development, stormwater design, water efficient landscaping, heat island effect, and innovative design (USGBC, 2010; Carter and Fowler, 2008). Kula (2005) reports that vegetated roofs may count for up to 15 points under the LEED system depending upon how well the roof is integrated into other building systems.

At more localized levels of government, policies have been specifically crafted to encourage new vegetated roof projects, and this is where the most detailed green roof policies are found (Carter and Fowler, 2008). A few examples are provided. Portland, Oregon mandates that all new city-owned facilities include a vegetated roof with $70 \%$ coverage (PDC 2005). In Seattle, an urban agriculture program encourages residents to grow their own food, including on rooftops, and allows them to sell it (Nolan, 2010). Chicago has incorporated vegetated roof language into 
their municipal energy code for the purposes of mitigating the urban heat island (Carter and Fowler, 2008).

A comprehensive literature review was completed to determine if any research or guidance exists regarding worker safety on vegetated roofs. There is no guidance in the peer-reviewed literature on occupational safety and health risks and the design of vegetated roofs (Behm, 2011). Previous review of green and vegetative roof guidelines found that the Singapore Centre for Urban Greenery \& Ecology's (CUGE) Design for Safety for Rooftop Greenery provided the only recommended guidelines for worker safety and its focus was on design of the built environment (Behm, 2011).

The focus of this technical note is to present original information and to summarize innovative safe design techniques for vegetated roofs. Safe design, or Prevention through Design (PtD) as termed by the United States' National Institute for Occupational Safety and Health (NIOSH) is established a primary method to counteract risk within all industries. There is a broad foundation of research and international government policy in PtD particularly for the built environment. Within this technical note, a detailed literature review on safe design is not provided. For background and literature reviews on this topic we suggest Aires et al (2010), Breslin (2007), Behm (2005), and Driscoll et al (2005). In the regulatory scheme, European regulations require designers to take a role in construction and maintenance worker safety and health (European Council, 1992). In the United States, regulation in this area appears unlikely in the short term; however, $\mathrm{NIOSH}$ commenced a PtD national initiative with the goal of influencing and infusing safe design into mainstream thinking and practice (Schulte et al., 2008).

A detailed vegetated roof guidelines review and a brief summation on the site visit findings were reported in a conference proceeding (Behm, 2011). This technical note expands on the site visit 
findings by describing the issues in greater detail and relating the observations to the development of specific safe design suggestions.

\section{Methods}

The objective of this research was to establish knowledge by collecting observational data to describe hazards and risks associated with vegetated roof maintenance for the purpose of developing safe design recommendations that stem from previous literature reviews and international guidelines. The author's interest in vegetated roof safety commenced when a colleague reported that an observation was made of landscapers 'hanging over' the edge of a six-story building hoisting up a lawn mower to the roof.

Nineteen buildings with vegetated roofs were visited in Portland $(n=9)$, Chicago $(n=5)$, and the mid-Atlantic region $(n=5)$. A contact at the United Union of Roofers, Waterproofers and Allied Workers in Washington D.C. recommended Chicago and Portland as cities where green roofs were increasing in popularity due to city tax incentives for green construction and roofs in particular. A contact with the local roofers union in Chicago arranged site visits. In Portland, a contact with a large construction company provided the names of a roofing company, landscape architects, landscapers, and a large developer. In the mid-Atlantic region, a contact at a university allowed four roof visits, and one other visit to a roof that was available to be accessed from public areas. The visits were a convenient sample and were limited by funding as this was a pilot study.

Observational research is the attentive watching and recording of somebody or something in a systematic way to establish knowledge and is an important tool in problem finding (Skaggs, 
2005). Observational research was chosen over other information gathering methods (surveys, focus groups, etc.) because the purpose was to establish knowledge about safety in this growing area of green design. Further, observing potential hazards and risks within the built environment allowed a more comprehensive understanding of the problem as it relates to design.

Roofs were evaluated following the parameters set forth in the CUGE safe design guidelines (CUGE, 2010). Specifically, observations were recorded with a focus on the design of the built environment including: safe access, roof edge protection, proximity of vegetation to hazardous machinery (mechanical and electrical systems), and proximity to skylights. While most of the identified hazards centered on falls, observations were not limited in that aspect. A checklist was developed and reviewed with the partners who provided access. This provided evidence of face validity. Photographs of the site hazards and layout provided a source for reflection on written notes. Discussions with landscape architects, roofers, landscapers, and building managers who accompanied the researcher provided insight into other hazards unique to the specific work to be performed (i.e., proper water access for the vegetation). From the observations, discussions with the green roof professionals, and the literature the design suggestions were developed. The conversations were open ended and the checklist was used as a guide to talk about the design of the built environment. The data collection protocols were reviewed and approved by the author's Institutional Review Board.

\section{Results and Design Suggestions}

\section{Access}


Two of the buildings' roofs were roof gardens at ground level; these are classified as roofs because they were built above lower grade building structures. These are accessible by the occupants of the building. There were no access issues, or other safety and health hazards, identified with the design of the built environment. The other 17 building's roofs can be classified as extensive roofs. Six of those roofs were judged to have poor access; two of these roofs are not maintained any more due to unsafe access, and another is maintained sporadically and not as frequently as the building occupants would like. One building's four separate vegetated roofs are only accessible through the bathrooms, above a toilet, and through a small hatchway. Personal access via fixed stairways from within the building's core is seen as optimum. Equipment access must be given special attention.

Another building, a high-rise condo, had extensive vegetated roofs at lower levels for occupant viewing, but not accessible by the occupants. For maintenance and inspection purposes, the roof area is accessible through a tenant's apartments. The tenant in this case is the Building Property Manager. Access is over an approximate 6 foot wall. According to the Building Property Manager, an A-framed type ladder is utilized to gain access to the roof. In terms of access for maintenance and landscapers, it seems burdensome to access work areas through an individual's apartment rather than designing in a separate and fixed access to the roof. A second building, a high-rise for elderly living with healthcare on lower floors presented a similar quandary for its lower level vegetated roof. The only access to this roof was through the healthcare area, which happened to be the Alzheimer's unit. This design poses potential safety issues for maintenance workers and possibly even for patients and healthcare workers.

\section{Design suggestions - Safe Access}

Option \#1. Design designated fixed stairs to the roof through the building's core so that workers and necessary equipment can access the roof in a safe and efficient manner. 
Option \#2. Where interior stairs are not designed into the structure for worker roof access, an exterior building caged ladder should be designed for roof access. Designation of a rooftop storage area for maintenance equipment is recommended if this option is used. See US OSHA regulations, 29 CFR 1910.27 for specifications on caged ladder design. Reliance on this option could limit the safe access of equipment.

\section{Fall Protection}

Ellis (2001) specifies a hierarchy of fall protection solutions. In order of preference they include: 1) eliminating fall hazards, 2) preventing fall hazards by guarding, 3) using fall arrest systems, and 4) applying administrative techniques (i.e. a second worker as a monitor). Similarly, in designing fall protection systems, the U.K.'s Health and Safety Executive (2008) recommends passive systems such as nets, guardrails, and parapets (where the individual does not have to do anything to activate the system) over active systems such as harnesses (where the worker has to clip on). A work-restraint system (i.e., harness with a short lanyard, which means it is impossible for the operative to get to a position where they could fall) is preferred over fall arrest systems as they do not prevent the fall, require rescue, and require the worker to have proper equipment (harness and lanyard) and to properly utilize the system and equipment (HSE, 2008). Potential fall protection hazards were observed on 11 of the 19 roofs visited. Five of the roofs had no fall protection measures at all. Four of the roofs had davits available; these however are installed for window washing and are not readily available in areas where workers needed them. Two of the roofs had partial 39" tall parapets; the lack of consistency on a roof is potentially deceiving to workers.

\section{Design suggestions - Fall prevention / protection}

Option \#1. Specify a minimum 39" parapet around the roof perimeter to serve as fall protection during vegetated roof installation, inspection, and maintenance. 
Option \#2. Specify a minimum 39" guardrail around the roof perimeter to serve as fall protection during vegetated roof installation, inspection, and maintenance.

Option \#3. Where parapets or guardrails are not specified as in option \# 1 or \#2, specify roofedge restraint systems that limit work where workers could fall.

Option \#4. Where parapets or guardrails are not specified as in option \#1 or \#2 and roof restraint system are not specified as in option \#3, specify that horizontal lifeline systems be installed.

a) On flat roofs, the system must be at least 6 feet from the roof's edge, and accessed easily from the fixed stairs through the building's core such that the entrance on to the roof facilitates the system's access ensuring the worker does not need to be within 6 feet of the edge unattached.

b) On sloped roofs, the system must be able to be accessed immediately when stepping onto the roof.

Option \#5. Where no other fall protection is designed into a flat roof, specify vegetation and any rock or decorative border be installed 12 feet from the roof's edge and that the 12 foot border be of a flat traditional roof surface (i.e., not the rock border) to ensure that weeding or other vegetative roof work does not take place within 12 feet of the roof's edge. This form of fall protection would only be acceptable if there is access to the roof through the building's core leading to the center of the roof, and if water spigot(s) are available on the roof within 12 feet of the roof's edge. In other words, the work to be performed on the roof should not encourage workers to be within 12 feet of the roof's edge at any time. Twelve feet is generally recommended by Ellis (2001).

Additional fall protection consideration. Where vegetation is hanging over the edge of a building's roof (trees, ivy type plants, etc.), ensure that a horizontal lifeline system or approved anchorage is available near the projected work. Even if a 39" tall parapet is available here, the 
scope of the maintenance work could encourage workers to use ladders or lean over rendering the parapet ineffective or to lean over the parapet to conduct the necessary work.

\section{Skylights and Unique Hazards}

For the 9-year period 1992-2000, Bobick (2004) reported that falls through skylights accounted for 150 U.S. workers fatalities. Fragile skylights adjacent to vegetation were observed at 2 building's roofs. Bobick (2004) suggests that best safety practice dictate that skylights should always be guarded by a screen or a standard guardrail, and reported that protective safety screen costs approximately $\$ 125$ and requires two workers about twenty minutes to install. Lewis (2009) reported that the American Society for Testing and Materials (ASTM) developed a work group to investigate the development of skylight fall-protection test standards.

Water access for irrigation was an issue at four roofs. For example, at one 20' roof with no parapet, no anchorages and poor access (vertical fixed ladder) through the middle of the building, a spigot was only available at ground level at one side. When the roof is to be watered there is an exterior spigot at the side of the building. A hose will have to be lifted / elevated to the roof and a worker will need to be positioned at the roof's edge and there are no provisions for fall protection anchoring. Understanding the work to be performed in relation to the vegetated roof is of the utmost importance. These issues can be solved by proper building design and planning.

\section{Design suggestions - Skylights and Unique building hazards}

1. When specifying rooftop vegetation, borders which need maintenance, and any irrigation system components near skylights or other fragile roof materials, consider specifying 
permanent guardrails around these roof openings or that the permanent protective screens within the skylight are installed to prevent falls through to lower levels.

2. Consider the roof and the work to be performed in relation to existing electrical power lines. Power lines should be moved or vegetation not be placed on roof areas where the work may encourage workers and their equipment to be within 10 feet of the overhead power line.

a. For lines and equipment energized at $50 \mathrm{kV}$ or less, the distance is 10 feet. US OSHA regulations 29 CFR $1910.269(k)(2)(i)(A)$

b. For lines and equipment energized at more than $50 \mathrm{kV}$, the distance is 10 feet $(305 \mathrm{~cm})$ plus 4 inches $(10 \mathrm{~cm})$ for every $10 \mathrm{kV}$ over $50 \mathrm{kV}$. US OSHA regulations 29 CFR $1910.269(k)(2)(i)(B)$

3. When specifying rooftop vegetation, borders which need maintenance, and any irrigation system components near other mechanical or electrical rooftop equipment, specify physical guards on that equipment to prevent accidental contact.

\section{Structural Integrity}

In early 2011, a green roof collapsed outside of Chicago, IL; fortunately no one was injured (Knapschaefer, 2011). Both the FLL and CUGE guidelines mention structural loads as issues to be considered in the design phase. ASTM develops and publishes numerous green roof standards including one for determining the dead load of green roof systems (ASTM, 2005). Dvorak and Volder (2010) advises that the thickness and water holding capacity of the growth media needs to correspond to the minimum requirements of the plant systems selected for the green roof while at the same time accommodate the structural integrity of the roof deck. Assuring structural integrity is a design consideration and can be a significant cost if the structure is found in need of upgrade. This research did not evaluate whether proper design load calculations were made on the buildings visited, and is a limitation of the research. Design recommendations made with regard to structural integrity are based on the literature review. 


\section{Design suggestion - Structural Integrity}

Ensure a structural engineer has established the maximum load bearing capacity of the roof; design planting and greenery to ensure this is not exceeded during installation and maintenance.

\section{Discussion}

There may be a belief that vegetated roofs utilizing native plants require such little maintenance that safety and health issues are insignificant after installation. All roofs visited planted native species and/or slow growing sedums. Despite this, twelve of the seventeen extensive roofs had a sprinkler system installed. Further, native species are not necessarily more successful on green roofs than non-native species (Getter et al, 2009). While plants could not actually be native to urban rooftops, many plant species have evolved in extreme environments and are adapted to green roof conditions (Getter et al, 2009). Plant selection can certainly influence frequency of roof access and thus overall risk after installation; landscape architects and horticulturists specifying plants and planting locations should consider safe access as a design criterion. The discussions with the professionals who accompanied the researcher identified inspection of the vegetation and the watering systems as quarterly to monthly activities in the first two years and likely less thereafter; since many of the vegetated roofs in the U.S. are new, the long term maintenance frequency is still being addressed by the professionals talked to in this research. Weeding for new vegetation generally occurs at minimum semi-annually. Two of the roofs in this study were identified as beyond two years mature yet both still required semiannual weeding and use of the irrigation system during dry summer months. A visit to one roof 
with a landscaper revealed that mowing the sedum vegetation will be completed soon because the vegetation is getting too high and thick.

There is an increased frequency of roof access required to maintain vegetated roofs compared to a conventional roof; this was confirmed through the discussions with the building professionals who provided access. The maintenance of vegetated roof materials presents both unique hazards and an increased frequency to the roof, and thus represents an increased risk to workers. Vegetated roofs are not "maintenance free" (Luckett, 2010). Maintenance tasks are particularly prone to fall hazards and the inspection and maintenance of vegetated roofs is no exception. Cameron et al. (2007) suggests that the risk of falling is high in maintenance because of the temporary, short duration and often precarious nature of the tasks. This creates situations where workers can be tempted to accept high levels of risk especially when the task is short (Cameron et al., 2007).

\section{Relationship to NIOSH Priorities}

NIOSH has established a Safe Green Jobs initiative, recognizing that "with the heightened attention on green jobs and environmental sustainability, it is important to make sure that worker safety and health are not overlooked" (Schulte et al., 2010). Green is an entry point for new ideas and sustainable best practices - why not safety? Green best practices can have a "trickledown" effect or all industry effect. For example, safe design strategies for vegetated roofs (and all green roofs) can be applied to all roofing projects; demonstrate the best practices on green projects and translate to all. Additionally, the research supports NIOSH's National Occupational Research Agenda (NORA) Research/Research to Practice Goal 13.3.2: Within 4-6 years, develop methods to utilize the U.S. Green Building Council's (USGBC) Leadership in the Energy and Environmental Design (LEED) rating system and the sustainability movement to implement Construction Hazards PtD. 


\section{Parallel to Solar Installation}

According to recent solar installation fatality investigations from the California Department of Public Health's Occupational Health Branch $(\mathrm{OHB})$, some interesting parallels can be drawn to worker safety on vegetated roofs. The hazards and risks are similar due to the same work environment. According to $\mathrm{OHB}$, "as the use of solar energy continues to grow, an increasing number of workers are exposed to unique hazards that they should be protected from. In 2008 and 2009, CA's Fatality Assessment and Control Evaluation program investigated the deaths of three solar panel installers. One of the workers died when he was electrocuted by an overhead power line, another fell through a skylight, and the third worker fell off a roof." Although this research did not discover any instances of deaths due to work on vegetated roofs, similar hazards and risks exist. Many of the design suggestions offered from this research can be utilized to eliminate and minimize risks during rooftop solar panel installation.

\section{Conclusions}

This research focused on a particular green building element to study from a safe design perspective. A summary of PtD suggestions have been created from this research and include considerations for structural integrity, fall prevention/protection, safe access, and unique building hazards. This research adds to the body of knowledge by relating observational data to describe hazards and risks associated with vegetated roofs during installation and maintenance to design. Architects, engineers, landscape architects, and other vegetated roof systems professionals should take into account to the safety of installers and future maintenance workers in the design of the built environment and rooftop vegetation. 
Green building certification organizations should use these design suggestions and include the safe design of vegetated roofs as a precondition for credit allowance. In other words, an unsafely designed vegetated roof perhaps should not receive green building credits regardless of the environmental benefit. This would complement NORA goal 13.3.2. Since the PtD concept is not a standard practice in the US, the suggested design considerations should be implemented, measured, and validated for their feasibility amongst the design community and for their impact on cost, schedule, and safety on vegetated roof projects.

The small sample size in the rooftop observations, due to funding limitations, is a limitation to the research. However, the findings are congruent with the CUGE safe design guidelines as themes around access and fall protection were found. The small sample size is an opportunity for future research and additional data should be collected to supplement this research endeavor. Nevertheless, the implementation, measurement, and validation of the safe design suggestions are viewed as a higher priority.

\section{Acknowledgement}

This study was funded by the Virginia Tech Occupational Safety and Health Research Center through the Kevin P. Granata Pilot Program funded by the Institute for Critical Technology and Applied Sciences. The author appreciates the support of the Center and the partners who provided access to vegetated roofs.

\section{References}


Aires, M.D.M., Gomez, M.C.R., \& Gibb, A. (2010). Prevention through design: The effect of European Directives on construction workplace accidents, Safety Science 48(2): 248-258.

American Society for Testing and Materials (ASTM) (2005). Standard Practice for Determination of Dead Loads and Live Loads Associated with Green Roof Systems. E2379-05. West Conshohocken, PA

Behm, M. (2011). Rooftop Vegetation: An Opportunity to Influence Green Buildings via Prevention through Design. CIB W99 2011 International Conference - Prevention: Means to the End of Construction Injuries, Illnesses, and Fatalities. Washington, DC. August 24-26, 2011. \{Recently accepted paper\}

Behm, M. (2005). Linking Construction Fatalities to the Design for Construction Safety Concept. Safety Science 43(8): 589-611.

Breslin, P. (2007). Improving OHS Standards in the Building and Construction Industry through Safe Design. Journal of Occupational Health and Safety - Australia and New Zealand 23(1): 89-99.

Bobick, T. (2004). Falls through Roof and Floor Openings and Surfaces, Including Skylights: 1992-2000. Journal of Construction Engineering and Management, 130 (6), 895-907.

Carter, T. and Fowler, L. (2008). Establishing Green Roof Infrastructure Through Environmental Policy Instruments. Environmental Management, 42 (1), 151-164. 
Castleton, H., Stovin, V., Beck, S., and Davison, J. (2010). Green roofs; building energy savings and the potential for retrofit. Energy and Buildings, 42 (10), 1582-1591.

Cavanaugh, L. (2008). Redefining the Green Roof. Journal of Architectural Engineering, 14 (1), 4-6.

Centre for Urban Greenery \& ecology (CUGE) (2010). Guidelines on Design for Safety on Rooftop Greenery. CS E02:2010. Singapore National Parks Board, May 2010.

Driscoll, T., Harrison, J., Bradley, C, \& Newson, R. (2005). Design Issues in Work-Related Serious Injuries. Department of Employment and Workplace Relations, Commonwealth of Australia.

Dvorak, B. and Volder, A. (2010). Green roof vegetation for North American ecoregions: A literature review. Landscape and Urban Planning 96, (4), 197-213.

Ellis N. (2001). Introduction to Fall Protection, $3^{\text {rd }}$ edition. American Society of Safety Engineers: Des Plaines, IL.

European Council (1992). The implementation of minimum safety and health requirements at temporary or mobile constructions sites, Council Directive 92/57/EEC. http://eurlex.europa.eu/LexUriServ/LexUriServ.do?uri=CONSLEG:1992L0057:20070627:EN:PDF

Getter, K. L., Rowe, D.B., and Cregg, B.M. (2009). Solar radiation intensity influences extensive green roof plant communities. Urban Forestry \& Urban Greening. 8 (4), 269-281. 
Hilten, R., Lawrence, T., Tollner, E. (2008). Modeling stormwater runoff from green roofs with HYDRUS-1D. Journal of Hydrology, 358 (3-4), 288-293.

Knapschaefer, J. (2011). Forensics Team Seeks Cause of Midwest Green Roof Collapse. Engineering-News Record. February 17, 2011.

Kula R (2005). Green roofs and LEED credits. Green Roof Infrastructure Monitor 7:1. Spring 2005. http://www.greenroofs.org/pdf/GRIM_Spring2005.pdf

Kumar, R. and Kaushik, S (2005). Performance evaluation of green roof and shading for thermal protection of buildings. Building and Environment, 40 (11), 1505-1511.

Li, J., Wai, O., Li, Y., Zhan, J., Ho, Y., Li, J., and Lam, E. (2010). Effect of green roof on ambient $\mathrm{CO}_{2}$ concentration. Building and Environment, 45 (12), 2644-2651.

Lewis, J. (2009). Skylight fall protection: More than just the manufacturer's responsibility. Glass Magazine, 4, 2-3.

Luckett, K. (2009). Green Roof Construction and Maintenance. McGraw Hill: New York.

Mentens, J., Raes, D., and Hermy, M. (2006). Green roofs as a tool for solving the rainwater runoff problem in the urbanized 21st century? Landscape and Urban Planning, 77 (3), 217-226.

Nolan, C. (2010). Richard Conlin: Sponsor of Seattle's New Urban Agriculture Policy. Living Architecture, 12 (4), 4-5. 
Portland Development Commission (PDC) (2005). Green Building Policy Guidelines. Available at http://www.pdc.us/pdf/dev_serv/green-building-guidelines.pdf. Accessed December 2010.

Rizwan, A., Dennis, L., and Liu, C. (2008). A review on the generation, determination and mitigation of Urban Heat Island. Journal of Environmental Sciences, 20 (1), 120-128.

Schulte, P., Heidel, D., Okun, A., and Branche, C. (2010). Editorial: Making Green Jobs Safe. Industrial Health, 48, 377-379.

Schulte, P., Rinehart, R., Okun, A., Geraci, C., and Heidel, D. (2008). National Prevention through Design (PtD) Initiative. Journal of Safety Research, 39 (2), 115-121.

Skaggs, P. (2005). Observational Research: Formalizing Curiosity. Joining Forces, University of Art and Design, Helsinki. September 22-25, 2005.

http://www.uiah.fi/joiningforces/papers/Skaggs.pdf

Takebayashi, H. and Moriyama, M. (2007).Surface heat budget on green roof and high reflection roof for mitigation of urban heat island. Building and Environment, 42, (8), 2971-2979.

Villarreal, E. and Bengtsson, L. (2005). Response of a Sedum green-roof to individual rain events. Ecological Engineering, 25 (1), 1-7.

Yang, J., Yu, Q., and Gong, P. (2008). Quantifying air pollution removal by green roofs in Chicago. Atmospheric Environment, 42 (31), 7266-7273. 